\title{
GREEN SYNTHESIS AND ANTIBACTERIAL ACTIVITY STUDIES OF SILVER NANOPARTICLES FROM THE AQUEOUS EXTRACTS OF WRIGHTIA TINCTORIA
}

\author{
Kripu Sharma V, Raji P, Divya Kumar M, Bennet Rohan D, \\ Ratna Geethika Gandham, Keerthana D, Karishma S,
}

Department of Biotechnology, Sathyabama Institute of Science and Technology, Jeppiaar Nagar, Rajiv Gandhi Salai, Chennai, India

\section{Antony V Samrot*, Sajeesh Pattammadath, Sajna Keeyari Purayil}

Department of Biomedical Sciences, Faculty of Medicine and Biomedical Sciences, MAHSA University, Jalan SP2, Bandar Saujana Putra, 42610 Jenjarom, Selangor, Malaysia

\section{Appalaraju, V.V.S.S}

Department of Medicinal Chemistry, Faculty of Pharmacy, MAHSA University, Jalan SP2, Bandar Saujana Putra, 42610 Jenjarom, Selangor, Malaysia.

*Corresponding Author Email id: antonysamrot@gmail.com

\begin{abstract}
Silver nano particles synthesised from the leaves of Wrightia tinctoria were characterised by following instrumental analysis - UV Vis spectroscopy, Scanning Electron Microscopy, Energy dispersive X-ray spectroscopy, Atomic force microscopy and $X$-ray diffraction. The interaction of the silver nanoparticle to the microorganism was studied in Pseudomonas aeruginosa and Bacillus subtilis through agar diffusion method, minimum inhibitory concentration, swarming motility assay and protein leakage assay. The nanoparticles were found to be more effective against the bacteria used in this study.
\end{abstract}

Keywords: Silver nanoparticles, Antibacterial activity, MIC, Protein leakage assay, Wrightia tinctoria.

Cite this Article: Kripu Sharma V, Raji P, Divya Kumar M, Bennet Rohan D, Ratna Geethika Gandham, Keerthana D, Karishma S, Antony V Samrot, Sajeesh Pattammadath, Sajna Keeyari Purayil, Appalaraju, V.V.S.S, Green Synthesis and Antibacterial Activity studies of Silver Nanoparticles from the Aqueous Extracts of Wrightia Tinctoria, International Journal of Advanced Research in Engineering and Technology (IJARET), 10 (6), 2019, pp 80-88.

http://iaeme.com/Home/issue/IJARET?Volume $=10 \&$ Issue $=6$ 


\section{INTRODUCTION}

The use of plants in medicine is an age hold practise documented well in Bible, Vedas, inscriptions etc., Plants are enriched with phytochemicals which confers wide range of bioactivities [1]. Plant secondary metabolites are organic compounds largely produced for various purposes like defence, communication, enzyme catalysis etc., although these are not directly involved in the growth and development of the plant secondary metabolites are used as drug excipients, food colourants, flavouring agents, perfumery and other industrial materials [2].

Wrightia tinctoria is a flowering plant of belonging to the Apocynaceae family [3]. This deciduous perennial plant producing milky white latex [4] has prominent therapeutic properties to cure piles, skin diseases especially psoriasis $[5,6]$. The plant in a crude form was found effective to control infections of diarrhoea, dysenteric, helminth, dandruff etc $[7,8,9]$. Further they also possess febrifuge, aphrodisiac and anti-ulcer properties [10-12]. The beneficial effect of the plant is the result of diverse phytochemicals present in them. The seed pod has the terpene wrightial, vcyclo eucalenol and cycloartenol. Flavonoids like tryptanthrin, rutin, isatin, indigotin and indirubin are isolated from the leaf extracts while lupeol, campesterol, stigmasterol were extracted from the stem [13]. Compounds like tryptanthrin, indigotin, anthranilate, istin, indirubin and rutin are also reported from this species. Tryptanthrin and triacontanol are the compounds isolated from the leaf extract of Wrightia tinctorial $[14,15]$. The present study is focused on the green synthesis and characterisations of silver nanoparticles from the crude extracts of Wrightia tinctoria and tests it for antimicrobial effect on the Gram positive and Gram negative organisms.

\section{MATERIALS AND METHODS}

\subsection{Preparation of Plant Extracts}

Wrightia tinctoria leaf was collected and herbarium was made. It was then authenticated by Dr. P Jayaraman, Director, Plant Anatomy Research Center, Chennai. Dried plant sample was allowed to interact with boiling water to get the aqueous extract. The filtered contents are then stored in $4^{\circ} \mathrm{C}$.

\subsection{Synthesis of Silver Nanoparticle}

The nano synthesis from metal halide was initiated by allowing the plant extract to reduce silver nitrate to silver nanomaterial in dark for $24 \mathrm{~h}$. The formation of the nanomaterial was noted by the change in the colour of the solution to brown from a pale yellow. The particles were procured by centrifugation and lyophilised to be stored in $4^{\circ} \mathrm{C}[16]$.

\subsection{Characterization of Silver Nanoparticles}

Spectral data were obtained by subjecting the nanoparticle for instrument analysis to note the absorbance in UV-Visible spectroscopy (UV - 1800 Shimadzu, Japan), transmittance in FTIR (Alpha Bruker optic Gmbh instrument) for the range 4000-400 cm-1, size of the particle from Scanning Electron Microscopy (Zeiss, GeminiSem) and elemental makeup in EDX spectrometry, crystallinity in X-ray diffraction (XRD) unit for $20^{\circ}-80^{\circ}$ at $2 \theta$ angles.

\subsection{Interaction Studies carried out on Microorganisms}

The response of the microorganism in a nano surrounding was tested on Pseudomonas aeruginosa and Bacillus subtilis for the concentration $2 \mu \mathrm{g} / \mathrm{mL}$ to $16 \mu \mathrm{g} / \mathrm{mL}$ and the results compared to Erythromycin [17]. The Minimum inhibitory concentration of the silver nanoparticle was undertaken through micro dilution method with the concentration range 
( 0.25 to $2 \mu \mathrm{g} / \mathrm{mL})$. The interaction of the nanoparticle in the motility of the microorganism was assessed by Swarming motility assay for the concentration $(0.5 \mu \mathrm{g} / \mathrm{mL})[18]$. Further the nanoparticle contact interaction on the microbes were tested by Protein leakage assay for Pseudomonas aeruginosa and Bacillus subtilis[19].

\section{RESULTS AND DISCUSSION}

\subsection{Characterization of Silver Nanoparticles}

The initiation of metallic silver formation from silver nitrate solution by reduction process was accounted by the change in colour of the solution to shady brown colour after being in contact with the plant extract for $24 \mathrm{~h}$. The formation of silver nanoparticles was characterized by exposing to UV - visible spectrometry which showed the spectral peak between $250 \mathrm{~nm}$ $400 \mathrm{~nm}$ (Fig. 1) [20]. The FTIR analysis of the sample showed peaks at $3270 \mathrm{~cm}-1$ indicating the presence of O-H stretching, peaks at $2623 \mathrm{~cm}-1$ depicting C-H stretching. Peak at 1044 $\mathrm{cm}-1$ indicating $\mathrm{C}-\mathrm{N}$ amines and $\mathrm{N}=\mathrm{O}$ symmetry for a peak at $1358 \mathrm{~cm}-1$ (Fig. 2) [21]. The nanoparticles when exposed to the scanning electron microscopy highlighted the particles in the size range $30-60 \mathrm{~nm}$ (Fig. 3). The elemental silver confirmation was done in EDX analysis which gave a peak at $3 \mathrm{keV}$ (Fig. 4). Diffraction points of $38^{\circ}, 44.5^{\circ}, 64.81^{\circ}, 77.43^{\circ}$ corresponding to (111), (200), (220), (311) planes confirmed the crystalline structures in XRD (Fig. 5) analysis [22].

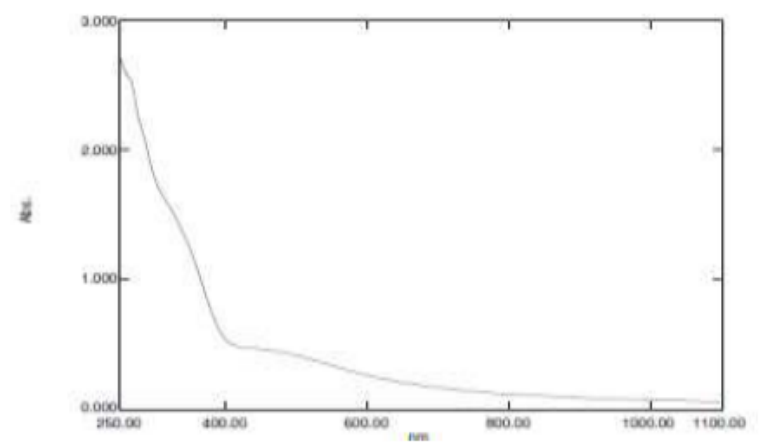

Figure 1 UV Visible spectroscopy of crude silver nanoparticles

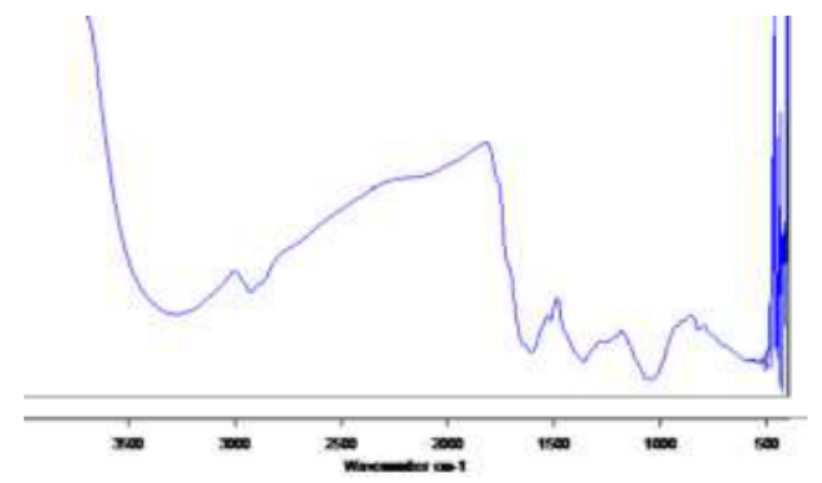

Figure 2 Fourier Transform InfraRed (FT-IR) spectroscopy of crude silver nanoparticles 
Green Synthesis and Antibacterial Activity studies of Silver Nanoparticles from the Aqueous Extracts of Wrightia Tinctoria

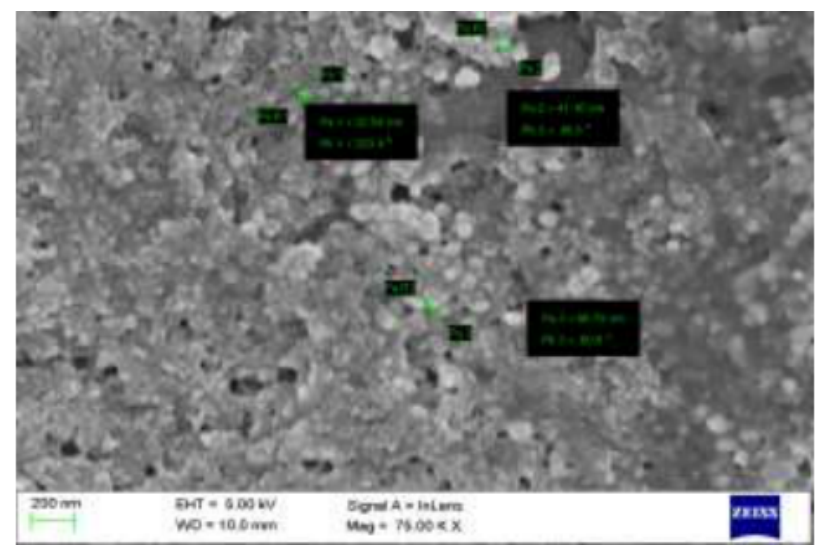

Figure 3 Scanning Electron Microscopy (SEM) of crude silver nanoparticles

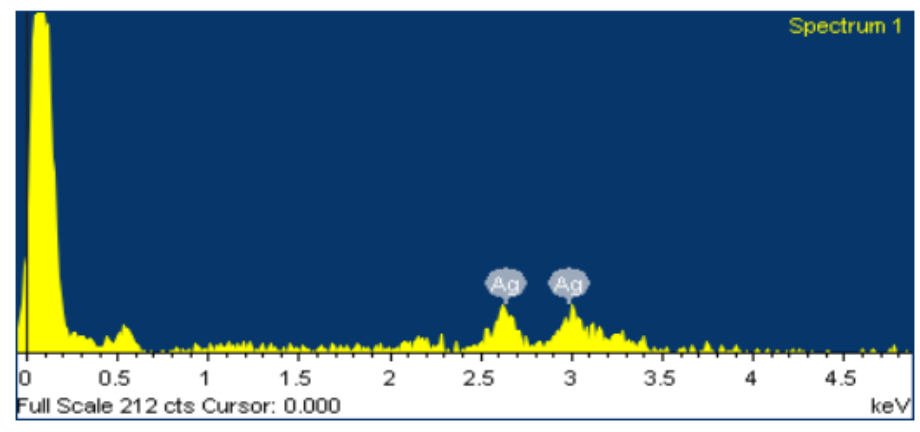

Figure 4 Energy Dispersive X-Ray spectroscopy (EDX) of crude silver nanoparticles

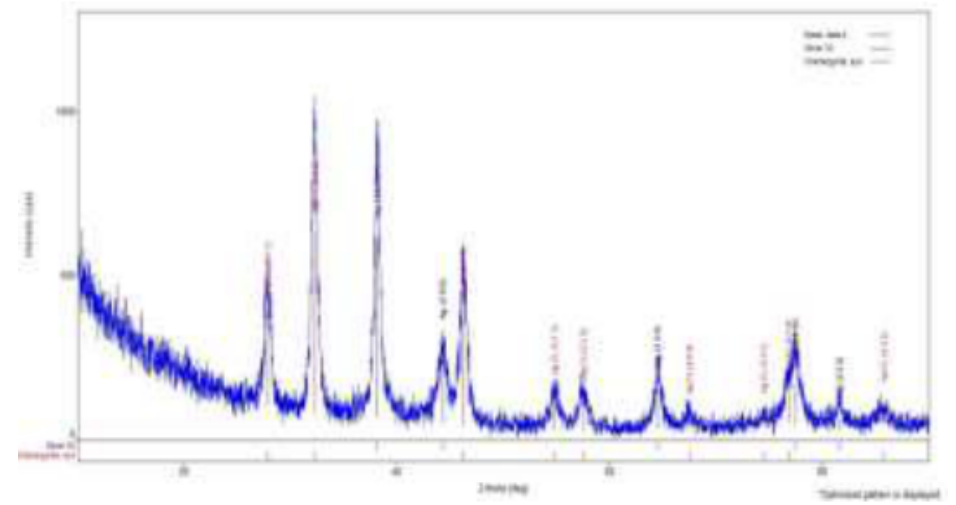

Figure 5 X-Ray Powder Diffraction (XRD) of crude silver nanoparticles

\subsection{Antibacterial Activity of Silver Nanoparticles}

The ability of the silver nanoparticles to inhibit the growth of both Gram-positive (Bacillus subtilis), and Gram-negative (Pseudomonas aeruginosa) bacteria is shown in (Fig 6). Pseudomonas aeruginosa had a clear zone of inhibition for all the study concentrations with the highest of $1.4 \mathrm{~cm}$ for $16 \mu \mathrm{g}$. (Table 1). Bacillus subtilis had $1.4 \mathrm{~cm}$ for $16 \mu \mathrm{g}$. The minimum concentration to inhibit Pseudomonas aeruginosa was $0.5 \mu \mathrm{g}$ whereas it was less than $0.25 \mu \mathrm{g}$ for Bacillus subtilis (Table 2). These studies on the antibacterial effect could be appropriately used in industrial applications, therapeutic formulations and environmental remediation studies [23, 24]. 


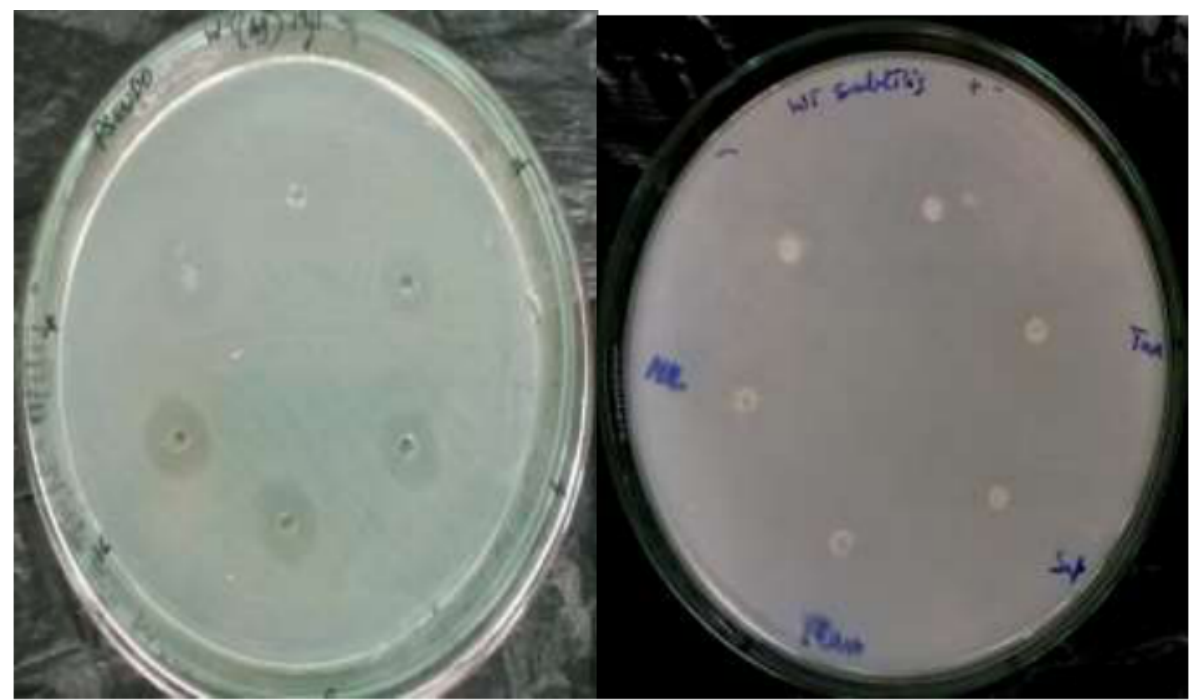

(a)

(b)

Figure 6 Antibacterial activity of crude silver nanoparticles against a) Pseudomonas aeruginosa b) Bacillus subtilis

Table 1: Antibacterial activity of crude silver nanoparticles against the micro organisms

\begin{tabular}{|c|c|c|}
\hline \multirow{2}{*}{ Concentration $(\boldsymbol{\mu g})$} & \multicolumn{2}{|c|}{ Zone of Inhibition (cm) } \\
\cline { 2 - 3 } & $\begin{array}{c}\text { Pseudomonas } \\
\text { aeruginosa }\end{array}$ & Bacillus subtilis \\
\hline 2 & 0.9 & 1.2 \\
\hline 4 & 1.0 & 1.3 \\
\hline 8 & 1.0 & 1.2 \\
\hline 16 & 1.4 & 1.4 \\
\hline Positive control (Erythromycin) & 1.0 & 1.6 \\
\hline Negative control (Solvent) & - & - \\
\hline
\end{tabular}

Table 2: Minimum Inhibitory Concentration (MIC) of crude silver nanoparticle

\begin{tabular}{|c|c|c|c|c|c|}
\hline \multirow{2}{*}{ S.No } & Bacterial species & \multicolumn{4}{|c|}{ Concentration $(\boldsymbol{\mu g} / \mathbf{m L})$} \\
\cline { 3 - 6 } & & 2 & 1 & 0.5 & 0.25 \\
\hline 1 & Bacillus subtilis & + & + & + & + \\
\hline 2 & Pseudomonas aeruginosa & + & + & + & - \\
\hline
\end{tabular}

\subsection{Swarming Motility and Protein Leakage Assay of Silver Nanoparticles}

The interaction of the nanoparticle onto the membrane of the organisms was analysed by protein leakage assay (Fig 7). The nanoparticle initially did not destabilise the membrane of Pseudomonas aeruginosa but upon $12 \mathrm{~h}$, the particles interferes with the organism resulting in seepage of cellular contents which is evident from the protein assay. The nanoparticle did not have much effect on Bacillus subtilis. However, the silver nanoparticles arrested the motility of both Pseudomonas aeruginosa and Bacillus subtilis. There are several reports for the efficient antibacterial activity of silver nanoparticles against bacteria[25-29]. 
Green Synthesis and Antibacterial Activity studies of Silver Nanoparticles from the Aqueous Extracts of Wrightia Tinctoria

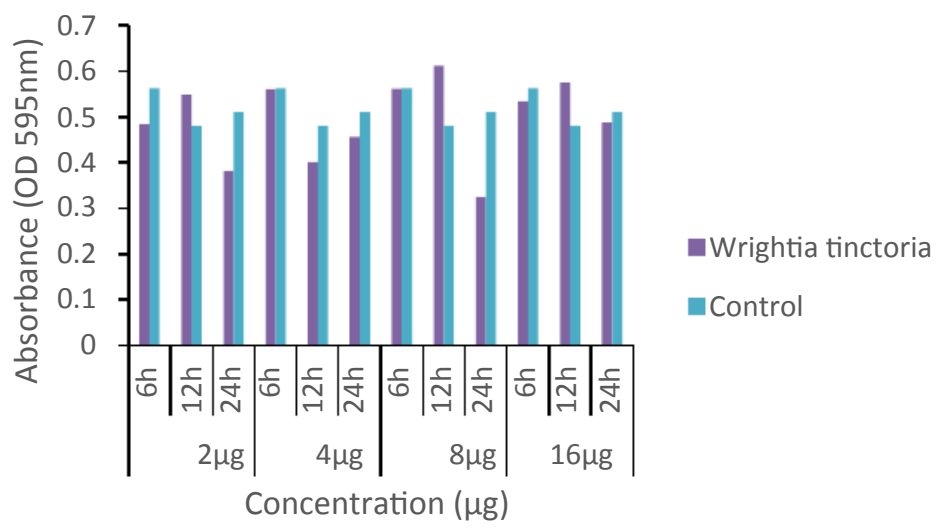

(a)

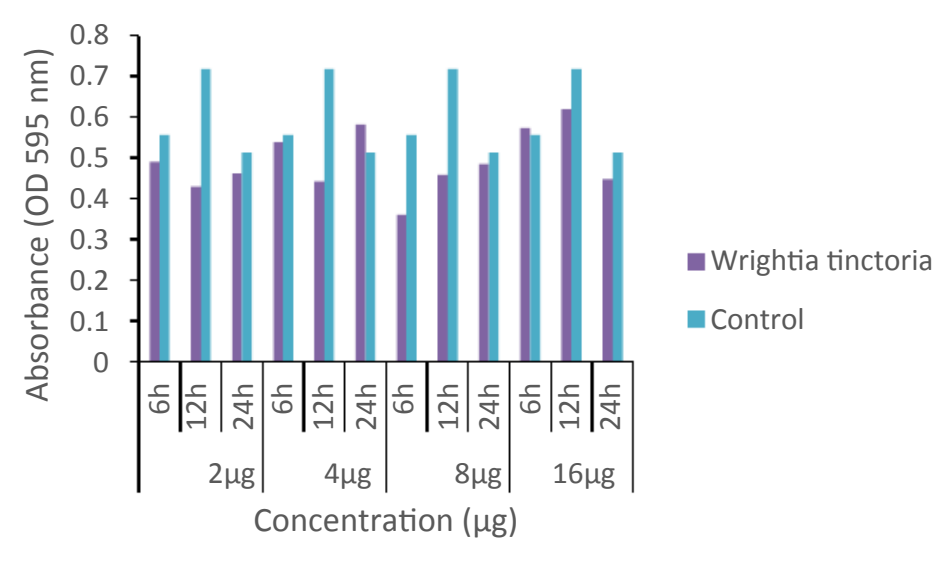

(b)

Figure 7 Protein leakage assay of crude silver nanoparticles a) Pseudomonas aeruginosa b) Bacillus subtilis

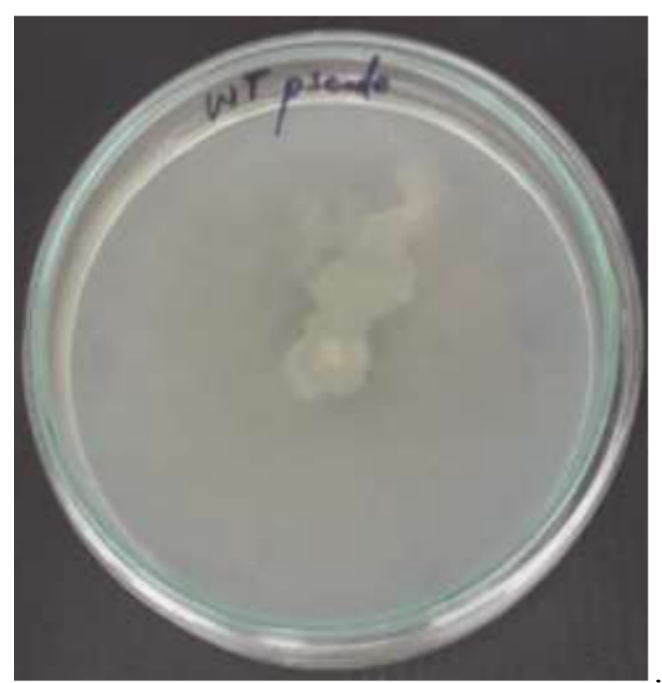

(a)

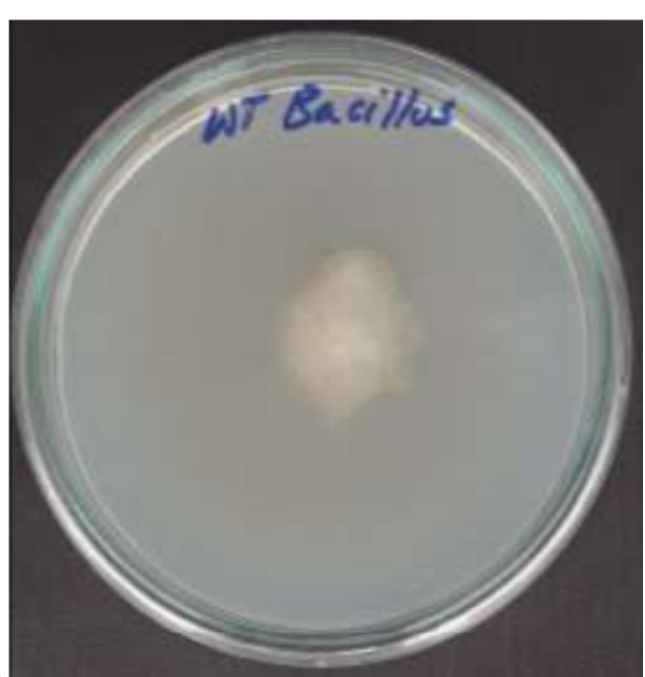

(b) 
Kripu Sharma V, Raji P, Divya Kumar M, Bennet Rohan D, Ratna Geethika Gandham, Keerthana D,

Karishma S, Antony V Samrot, Sajeesh Pattammadath, Sajna Keeyari Purayil, Appalaraju, V.V.S.S

Figure 8 Swarming motility of crude silver nanoparticle against a) Pseudomonas aeruginosa

b) Bacillus subtilis

\section{CONCLUSION}

The silver nano particles produced from the aqueous extracts of Wrightia tinctoria were crystalline particles having the size of $30-60 \mathrm{~nm}$. The nanoparticles were effective against both Gram positive and Gram negative microorganisms and significantly interfered with the motility of the microbes. With more studies on the safe dosage and administration, these particles can be used as an effective antimicrobial agent.

\section{ACKNOWLEDGEMENT}

All the authors acknowledge The Management, Sathyabama Institute of Science and Technology for providing the lab.

\section{AUTHOR'S CONTRIBUTION}

All the authors have made direct contribution on idea creation and research work. All the authors are involved in manuscript preparation.

\section{CONFLICT OF INTEREST}

The authors have no conflict of interest.

\section{FUNDING}

No fund was received from any funding agency

\section{DATA AVAILABILITY}

\section{N/A}

\section{ETHICS}

\section{N/A}

\section{REFERENCES}

[1] P. Raji, D. Keerthana, S. Karishma, K.S. Bhavya and A.V. Samrot, Indian Medicinal Plants and Its Therapeutic Importance with Special Reference to Thespesia populnea, Wrightia tinctoria: A Review, Current research in Biology, 1, 2019.

[2] J.T. Zhao, L.C. Davi, and R. Verpoorte, Elicitor signal transduction leading to production of plant secondary metabolites, Biotechnology Advances, 23, 2005, pp 283 - 333.

[3] I.M. Turner. William Roxburgh and the names of some Indian indigos. Willdenowia, 2014, 21-25.

[4] M.S. Khyade, and N.P. Vaikos, Comparitive phytochemical and antibacterial studies on the bark of Wrightia tinctoria and Wrightia arborea, International Journal of Pharma and Bio Sciences, 2(1), 2011.

[5] A. Dixit, A.K. Jain, P. Tiwari, N. Gupta, and P. Gangele, A phytopharmacological review on an important medicinal plant Wrightia tinctorial, current research pharmaceutical sciences, 4(3), 2014, pp 70-76.

[6] L. Devi, and M.C. Divakar, Wrightia tinctoria (Robx) R. Br. - An Updated Review. Hygeia. Journal for Drugs and Medicines, 6(12), 2014, pp 95-105.

[7] A. Shruthi, K.P. Latha, H.M. Vagdevi, B. Pushpa, and C. Shwetha, Anti-diabetic activity of the leaves extracts of Wrightia tinctoria on alloxan induced diabetic rats. Journal of Chemical and Pharmaceutical Research, 4(6), 2012, pp 3125-3128.

[8] V.P. Singh, V.P., S.K. Sharma, S.K., and Kare, V.S. Medicinal plants from Ujjain district Madhya Pradesh, part II. Indian Drugs Pharm Ind. 1980; 5, pp 7-12. 
Green Synthesis and Antibacterial Activity studies of Silver Nanoparticles from the Aqueous

Extracts of Wrightia Tinctoria

[9] G.Y. Dama, H.L. Tare, M.S. Gore, S.R. Deore, and J.S. Bidkar, Comparative helmintholytic potential of extracts obtained from Cymbopogon citratus and Wrightia tinctoria leaves, International Journal of Pharma and Bio Sciences, 2(1), 2011, pp 321-327.

[10] M. Sakthivadivel, P. Gunasekaran, J.T. Annapoorani, D.A. Samraj, S. Arivoli, and S. Tennyson, Larvicidal Activity of Wrightia tinctoria R. BR. (Apocynaceae) fruit and leaf extracts against the filarial vector Culex quinquefasciatus say (Diptera: Culicidae). Asian Pacific Journal of Tropical Disease, 4(1), 2014, pp 373-377.

[11] C.M. Divakar, and S.L. Devi, Antiulcer activity of Wrightia tinctoria (Roxb). R. Br. Der Pharmacia Sinica, 2(2), 2011, pp 355-360.

[12] Wail H. Ali, Controlled Morphology of Silver Nanoparticles by Etching Laser Wavelength, International Journal of Civil Engineering and Technology, 9(9), 2018, pp. 1791-1800.

[13] R. Srivastava, A review on phytochemical, pharmacological, and pharmacognostical profile of Wrightia tinctoria: Adulterant of kurchi. Pharmacognosy reviews, 8(15), 2014, pp 36.

[14] A.V. Muruganandam, S.K. Bhattacharya, and S. Ghosal, Indole and flavanoid constituents of Wrightia tinctoria, W. tomentosa and W. Coccinea. Indian Journal of Chemistry, 39(2), 2000, pp 125-131.

[15] Praful Kakde and S N Paul, Effect Of Alumina Nanoparticle Addition on the Mechanical and Wear Behaviour of Reinforced Acrylonitrile Butadiene Styrene Polymer, International Journal of Advanced Research in Engineering and Technology (IJARET), Volume 5, Issue 6, June (2014), pp. 185-192

[16] L. Devi, C. Madhu, and Divakar. Wrightia tinctoria (Robx) R. Br. - An Updated Review. Hygeia. J D. Med., 6(12), 2014, pp 95-105.

[17] V. George, Tryptanthrin from Wrightia tinctoria. Fitoterapia, 67, 1996, pp 553-554.

[18] A.V. Samrot, Silky, V.C. Ignatious, P. Raji, C. SaiPriya, and J.A. Selvarani, Bioactivity Studies of Datura metel, Aegle marmelos, Annona reticulata and Saraca indica and their Green Synthesized Silver Nanoparticle. Journal of Pure and Applied Microbiology, 13(1), 2019, pp 329-338.

[19] Ajeet Kumar, Mukesh Kumar, Yohannes Feyissa Beyisho and Vipul Kumar Sharma, Condensation Rate Enhancement of Fluid in Steam Condenser by Mixing Nanoparticles. International Journal of Thermal Engineering, 6 (1), 2018, pp. 1-9

[20] P. Raji, A.V. Samrot, D. Dharani, B. Alexander, In vitro and In silico Approaches to Study the Bioactivity of Citrus limon Leaf Extracts. Journal of Young Pharmacists, 9(2), 2017, pp 290295.

[21] K. Renugadevi, V. Aswini, and P. Raji, Microwave Irradiation Assisted Synthesis of Silver Nanoparticle Using Leaf Extract of Baliospermum Montanum And Evaluation of Its Antimicrobial, Anticancer Potential Activity. Asian Journal of Pharmaceutical and Clinical Research, 5, 2012, pp 283-287.

[22] M. Rajaram Narayanan, S. Nallusamy, Sri Lakshmana Kumar, Characterization of Machining Parameters on EN 31 with AL2O3 Nanoparticles Using Taguchi Technique, International Journal of Mechanical Engineering and Technology 9(1), 2018, pp. 1173-1183.

[23] K. Maruthai, K. Vallayyachari, T. Ravibalan, S.A. Philip, A.V. Samrot, and M. Muthuraj, Antibacterial activity of the Silver Nanoparticles against Escherichia coli and Enterobacter sp. Progress in Bioscience and Bioengineering, 1(1), 2017, pp 29-35.

[24] A.V. Samrot, B. Suvedhaa, C.S. Sahithya, and A. Madankumar, Purification and Utilization of Gum from Terminalia Catappa L. for Synthesis of Curcumin Loaded Nanoparticle and Its In Vitro Bioactivity Studies, Journal of Cluster Science, https://doi.org/10.1007/s10876-018$1412-4$. 
Kripu Sharma V, Raji P, Divya Kumar M, Bennet Rohan D, Ratna Geethika Gandham, Keerthana D,

Karishma S, Antony V Samrot, Sajeesh Pattammadath, Sajna Keeyari Purayil, Appalaraju, V.V.S.S

[25] K. Jyoti, M. Baunthiyal, and A. Singh, Characterization of silver nano particles synthesized usingUrtica dioicaLinn. Leaves andtheir synergistic effects with antibiotics, Journal of Radiation Research and Applied Sciences, 2016, pp 217-227.

[26] A.V. Samrot, J.L.A Angalene, S.M. Roshini, S.M. Stefi, R. Preethi, P. Raji, A. Madankumar, P. Paulraj, and S.S. Kumar, Purification, characterization and utilization of polysaccharide of Araucaria heterophylla gum for the synthesis of curcumin loaded nanocarrier, International Journal of Biological Macromolecules, 140, 2019.

[27] P. Raji, A.V. Samrot, K.S. Bhavya, M. Sharan, S. Priya, and P. Paulraj, Greener Approach for Leather Tanning Using Less Chrome with Plant Tannins and Tannins Mediated Nanoparticles, Journal of Cluster Science, https://doi.org/10.1007/s10876-019-01597-6.

[28] Dr. K.R. Aswin Sidhaarth and S. Baskar, A Review on Adsorption of Nickel and Mercury from Aqueous Solution using Nanoparticles, International Journal of Civil Engineering and Technology, 9(9), 2018, pp. 1246-1255.

[29] A.V. Samrot, J.L.A. Angalene, S.M. Roshini, P. Raji, S.M. Stefi, R. Preethi, A.J. Selvarani, and A. Madankumar, Bioactivity and Heavy Metal Removal Using Plant Gum Mediated Green Synthesized Silver Nanoparticles, Journal of Cluster Science, https://doi.org/10.1007/s10876-019-01602-y.

[30] Md. Aftabuddin Rasool, Md. Hafeezuddin, Shaik Sohail Arfath and Mohammed Ashwaq Miya, A Review on Magnetic Nanoparticles. International Journal of Mechanical Engineering and Technology, 7(6), 2016, pp. 528-534.

[31] A.V. Samrot, N. Shobana, S.S Kumar, and G. Narendrakumar, Production, optimization and characterisation of chitosanase of Bacillus sp and its applications in nanotechnology, Journal of Cluster Science, 30(3), 2019, pp 607-620

[32] A.V. Samrot, P. Raji, A.J. Selvarani, and P. Nishanthini, Antibacterial activity of some edible fruits and its green synthesized silver nanoparticles against uropathogen-Pseudomonas aeruginosa SU 18, Biocatalysis and agricultural biotechnology, 16, 2018, pp 253-270.

[33] A.V. Samrot, N. Shobana, and R. Jenna, Antibacterial and Antioxidant Activity of Different Staged Ripened Fruit of Capsicum annuum and Its Green Synthesized Silver Nanoparticles, BioNanoScience., 8, 2018, pp 632-646.

[34] Skariya P D, Satheesh M, Edwin Raja Dhas and Suneesh E, A Study of Pftig and Fbtig Welding Process on Bead Morphology Using Nanoparticles on 15cdv6 Steel, International Journal of Mechanical Engineering and Technology, 9(6), 2018, pp. 450-458

[35] P. Senthilkumar, S. Rashmitha, P. Veera, C.V. Ignatious, C. SaiPriya, and A.V. Samrot, Antibacterial activity of neem extract and its green synthesized silver nanoparticles against Pseudomonas aeruginosa. Journal of Pure and Applied Microbiology, 12(2), pp 2018.

[36] Dr. K.R. Aswin Sidhaarth, Dr.J.Jeyanthi, S.Baskar and Dr. M. Vinod Kumar, Adsorption of Congo Red Dye Using Cobalt Ferrite Nanoparticles, International Journal of Civil Engineering and Technology, 9(9), 2018, pp. 1335-1347.

[37] P. Raji, A.V. Samrot, D. Keerthana, and S. Karishma, Antibacterial Activity of Alkaloids, Flavonoids, Saponins and Tannins Mediated Green Synthesised Silver Nanoparticles Against Pseudomonas aeruginosa and Bacillus subtilis, Journal of Cluster Science, 30(4), 2019, pp 881- 895. 